\title{
Method for Measuring Error Establishment in 5-Axis Milling Machines with a Touch Probe
}

\author{
Tsvetan Kaldashev \\ Technical university of Sofia \\ Sofia, Bulgaria \\ email: kaldashev.cvetan@abv.bg
}

\begin{abstract}
The present paper proposes a method for measuring and compensating for error establishment. The measurement is done with a touch probe and the measuring program is a macro program. A mathematical model was developed to experimentally determine the error of nonalignment of the axis of rotation of the workpiece with the physical axis of rotation of mass $C$. A virtual approach to compensate for the error of establishment by using a postprocessor for the particular machine was also proposed.
\end{abstract} CNC.

Keywords - milling machine, measuring, touch probe,

\section{INTRODUCTION}

The use of touch probes greatly expands the capabilities of CNC machines. Their use reduces machine setup time, which increases accuracy. These measurement processes are fully automated. The measurement method consists in the fact that measurement is actually carried out by the $\mathrm{CNC}$ machine tracking system, and the measuring head only perceives the controllable magnitude. Impact on measurement accuracy is the precision of the machine's measuring system, scattering when the touch probe is working and its moving speed at the touch.

The leading manufacturers of CNC Fanuc, Sinumerik, Heidenhain and others. Offer dialogue cycles to measure and compensate for the set-up error. In Fanuc, command G54.4 is available [3].

\section{MEthod FOR MEASURING ERROR ESTABLISHMENT}

As an example, be considered a rotary die for sanitary absorbents (figure 1). Typical of them is that they have a higher productivity than those with reciprocating movement. The production of these tools is carried out on 4 and 5 axis CNC milling machines [5]

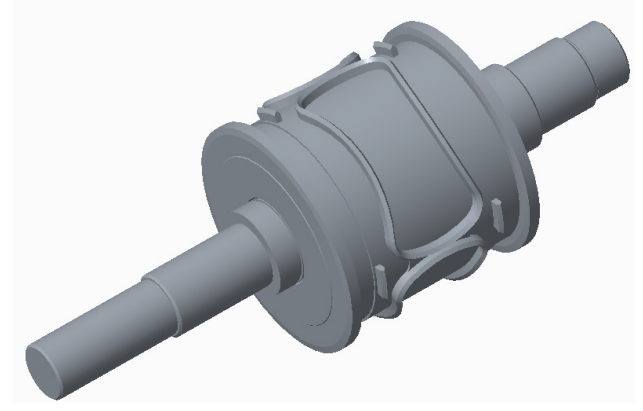

Fig. 1. Rotary die
After milling, the knives are hardened and the cutting contour is grinded with high-speed spindles with abrasive tapered head, mostly made of ultra-hard materials. The ultimate requirement is to achieve a long life of the contour. In the process of operation, the tool is worn out, which necessitates restoration of its cutting ability. This is done by grinding the outer cylindrical surface of a grinding machine where the setting is carried out between centers and the grinding on the side surface of the cutting contour is carried out on a machining center with a bearing on the bearing in a chuck. As a result of the change of the technological base, set-up errors are obtained, which must be compensated in order to obtain a uniform width of the cutting track. Significant influence on the precision of machining is due to the radial beating errors and the failure of the axis of the workpiece with the axis of rotation of the $\mathrm{C}$ axis. To measure these errors, a method is used to measure the touch probe in mass position $\mathrm{A}=$ $90^{\circ}$ (figure 2). The surfaces to which the radial beating is measured are the two supporting boards 1 and 2 of the workpiece. Measurement is performed through an angular pitch of $10^{\circ}$ on the $\mathrm{C}$ axis when it was at the point of the machine.

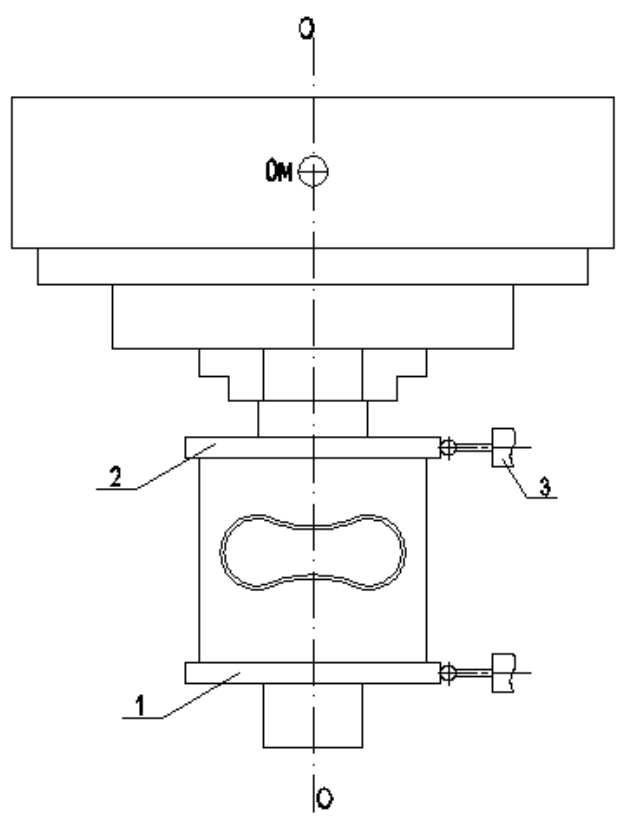

Fig. 2. Measuring radial beating with touch probe

Print ISSN 1691-5402

Online ISSN 2256-070X

http://dx.doi.org/10.17770/etr2019vol3.4190

(C) 2019 Tsvetan Kaldashev

Published by Rezekne Academy of Technologies.

This is an open access article under the Creative Commons Attribution 4.0 International License. 
Measuring motion is on axis $\mathrm{Z}$. The program on which the measurement is performed is a macro program. It is organized so that the minimum value of radial beating pmin is found within $180^{\circ}$. The instruction in DNC mode displays the measured minimum value and the angle Comin, which is measured relative to the machine's point of reference. For the determination of the maximum beating $\rho$ max, the workpiece is rotated at $180^{\circ}$ to the minimum beating angle, where the value is determined by measurement. Analogously, the values of $\rho$ min, C $\rho$ min, pmax and $\rho$ max for the second section are determined. The algorithm for the measurement is shown in figure 3. At the start, there is a check for calibration of the touch probe. The calibration is done with another macro program, where a bearing is pressed into the machine body as a reference. In the table 1 shows the measured values for one full part of the workpiece.

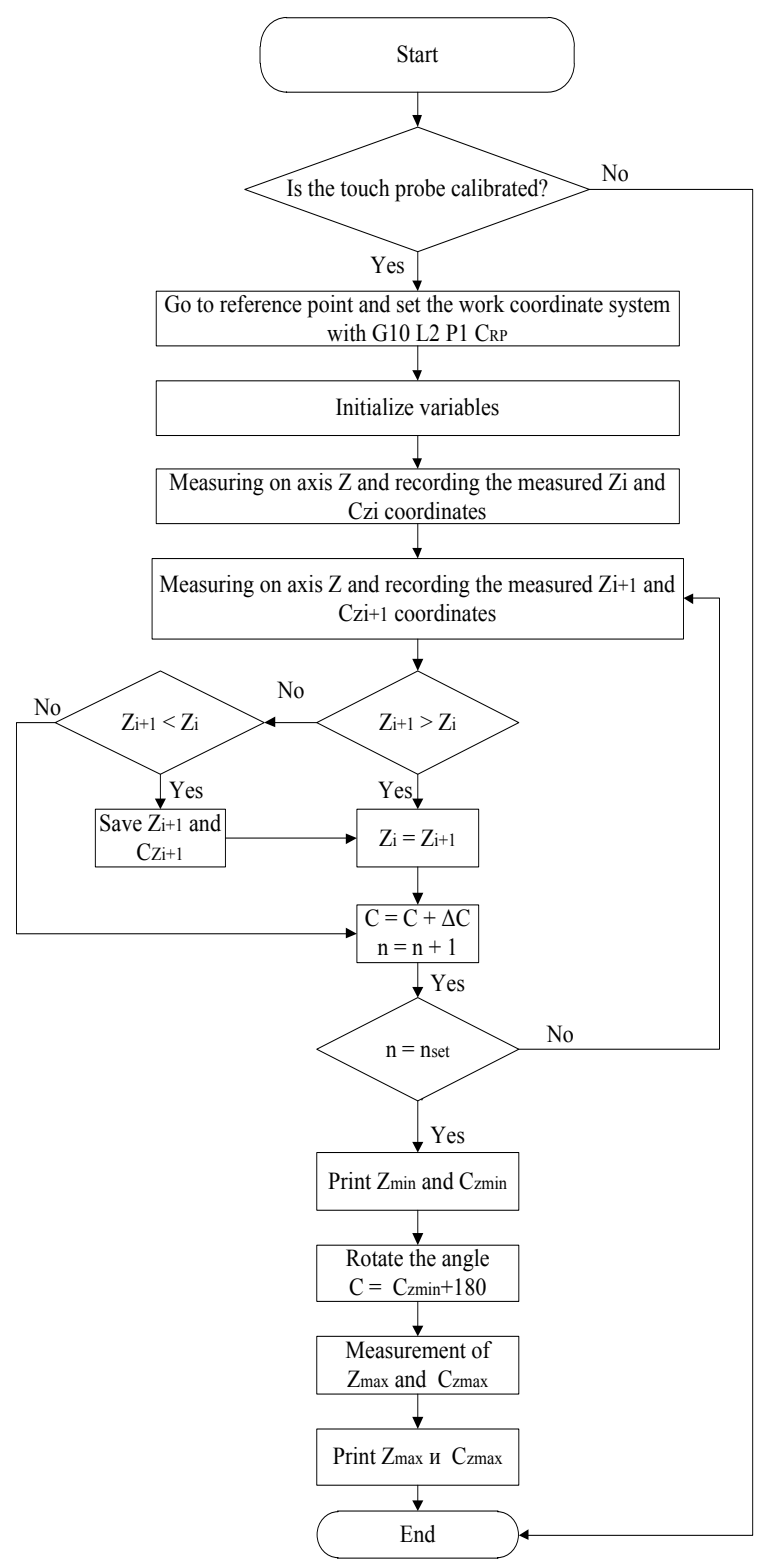

Fig. 3. Algorithm measuring program

In figure 4 shows the distribution of the radial beating of the workpiece relative to the axis of rotation of $\mathrm{C}$ axis.

\begin{tabular}{|c|c|c|c|c|c|}
\hline $\begin{array}{l}\text { Angle } \\
\text { of } \\
\text { rotation } \\
\text { on axis } \\
\mathrm{C}\left[{ }^{\circ}\right]\end{array}$ & $\begin{array}{l}\text { Measured } \\
\text { value } \\
\text { along the } \\
\mathrm{Z} \text { axis } \\
{[\mathrm{mm}]}\end{array}$ & $\begin{array}{c}\text { Angle } \\
\text { of } \\
\text { rotation } \\
\text { on axis } \\
\mathrm{C}\left[{ }^{\circ}\right]\end{array}$ & $\begin{array}{c}\text { Measured } \\
\text { value along } \\
\text { the } Z \text { axis } \\
{[\mathrm{mm}]}\end{array}$ & $\begin{array}{c}\text { Angle of } \\
\text { rotation } \\
\text { on axis } \\
C\left[^{\circ}\right]\end{array}$ & $\begin{array}{c}\text { Measured } \\
\text { value along } \\
\text { the } Z \text { axis } \\
{[\mathrm{mm}]}\end{array}$ \\
\hline 10 & 79.838 & 130 & 79.681 & 250 & 79.8 \\
\hline 20 & 79.83 & 140 & 79.683 & 260 & 79.814 \\
\hline 30 & 79.815 & 150 & 79.683 & 270 & 79.826 \\
\hline 40 & 79.795 & 160 & 79.683 & 280 & 79.846 \\
\hline 50 & 79.783 & 170 & 79.69 & 290 & 79.853 \\
\hline 60 & 79.765 & 180 & 79.696 & 300 & 79.858 \\
\hline 70 & 79.749 & 190 & 79.707 & 310 & 79.87 \\
\hline 80 & 79.734 & 200 & 79.725 & 320 & 79.873 \\
\hline 90 & 79.72 & 210 & 79.735 & 330 & 79.871 \\
\hline 100 & 79.705 & 220 & 79.752 & 340 & 79.87 \\
\hline 110 & 79.695 & 230 & 79.768 & 350 & 79.858 \\
\hline 120 & 79.685 & 240 & 79.789 & & \\
\hline
\end{tabular}

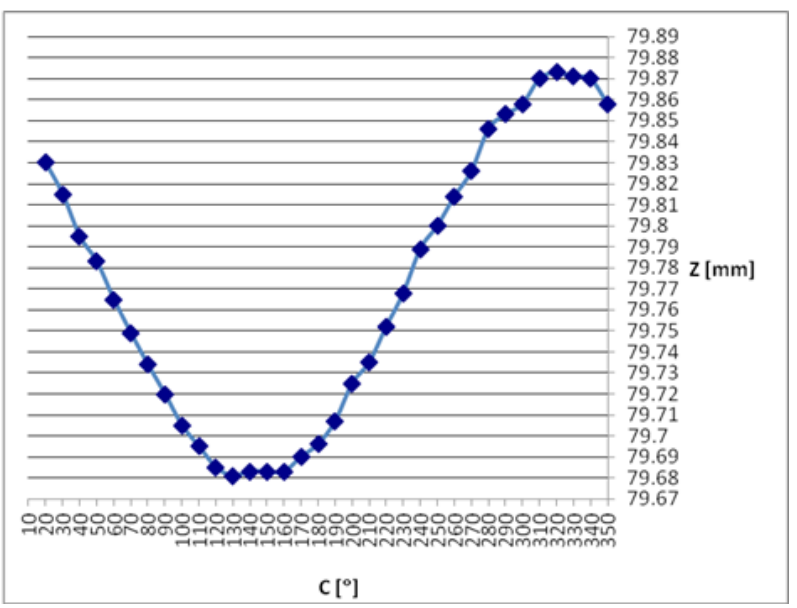

Fig. 4. The distribution of the radial beating of the workpiece relative to the axis of rotation of the $C$ axis

Measurement was performed at a feed rate of $30 \mathrm{~mm} /$ min, where the scattering of the result remained constant [4], [2].

After measuring the error [1] it is possible to compensate it. The detection error can be compensated by using the postprocessor for the particular machine being machined or in a manufacturing model to create a coordinate system rotated relative to the machine with rotation equivalents equivalent to the error. To calculate the error of non-alignment of the axis of the workpiece with the axis of rotation $\mathrm{C}$ axis, Microsoft Excel is used where the mathematical model of the error is introduced. Thus, after measurement with a touch probe, the minimum and maximum beating values and the angle at which they are measured are introduced into the mathematical model. On the basis of the analytical dependencies in the mathematical model the matrix giving the relation between the axis of rotation of the workpiece and the axis of rotation of the mass $\mathrm{C}$ is obtained. The values obtained are introduced into the matrix of generalized post-processor G-POST (figure 5). 


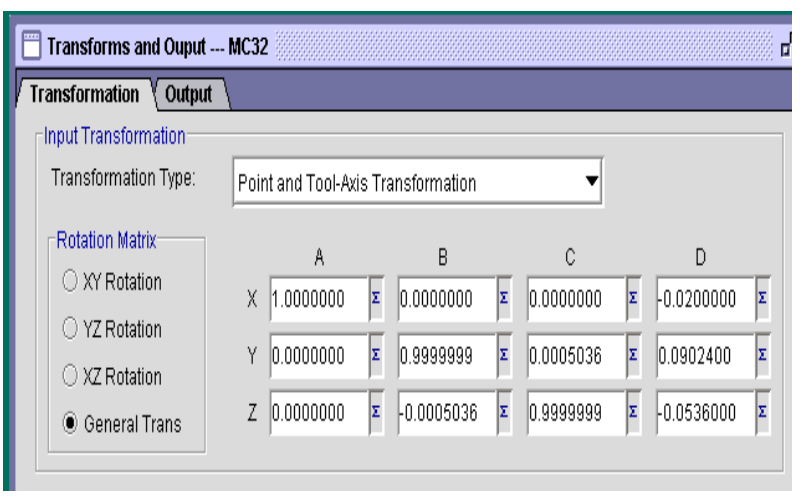

Fig. 5. Transforms and Output page of the generalized postprocessor $G$-POST with input compensation values

With the proposed method of measuring and compensating for the error of establishment, the grinding of the cutting edge of a rotating knife in a virtual environment (Vericut) was performed. The values with which the test was made are actually measured on the measuring headpiece according to the algorithm shown in figure 3 . In table 2 shows the measured radial beating values for the supporting board 1 and the supporting board 2 (figure 2 ) and the angle at which they are measured relative to a reference point of the machine.

TABLE II.

\begin{tabular}{|c|c|c|}
\hline & Supporting board 1 & Supporting board 2 \\
\hline & \multicolumn{2}{|c|}{ Measured values, mm } \\
\hline$\rho \min$ & 0.01 & 0.02 \\
\hline Comin & 170 & 140 \\
\hline$\rho \max$ & 0.16 & 0.03 \\
\hline Comax & 350 & 320 \\
\hline
\end{tabular}

After processing the workpiece in Vericut, the deviation (marked with a yellow color as a narrow strip) is seen as a result of the set-up error (figure 6). From figure 6 it is seen that as a result of the error, sections of the cutting contour are obtained where it is highly sharpened and sections in which it has a certain width. This is unacceptable in terms of the working ability of the instrument above certain limits.

The set-up error value is entered into the G-POST generalized postprocessor matrix, and then a control program is generated with the tool trajectory equidistant to the error. With the generated control programs, a "grinding" was performed on the side surfaces of the cutting track in Vericut's environment. In fig. 7 shows the result after processing the workpiece with a compensated set-up error with the postprocessor. From Fig. 7 it is seen that a relatively uniform width of the cutting track is obtained.

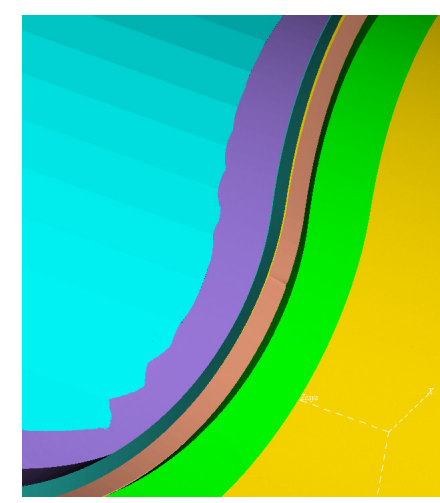

Fig. 6. Deviation of the width of the cutting path due to error of establishment of the workpiece

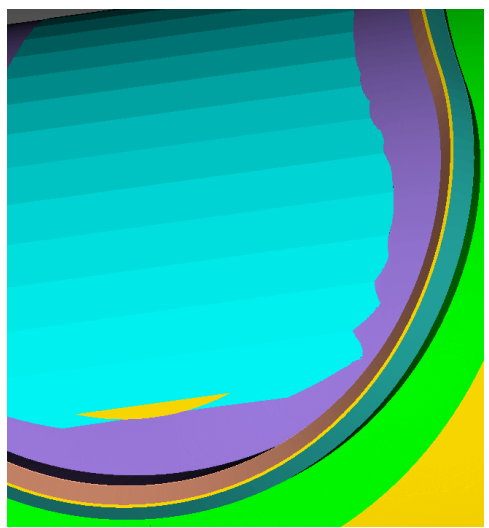

Fig. 7. The result of compensating the error in establishment with a postprocessor

After error compensation and grinding on the side surfaces of the cutting contour, a two-section measurement is performed with the $\mathrm{X}$-Caliper tool to determine the width of the cutting track. The results of the measurements are shown in table 3 , and the sections in which the measurement in figure 8 .

TABLE III.

\begin{tabular}{|c|c|c|}
\hline Section & Point & Measure value, $\mathbf{m m}$ \\
\hline \multirow{2}{*}{ I - I } & 1 & 0,279 \\
\cline { 2 - 3 } & 2 & 0,28 \\
\hline \multirow{2}{*}{ II - II } & 3 & 0,25 \\
\cline { 2 - 3 } & 4 & 0,13 \\
\hline
\end{tabular}

The measured value at point 4 shows a difference due to incorrect setting of the rotation angle relative to the machine reference point. The task is solved by recalculating the angle $\mathrm{C}$ on the axis, which is set as offset in the offset of the operating coordinate systems relative to the machine's pivot. The study, which is shown, refers to the most unfavorable case - a curvilinear contour located on a cylindrical surface, where on these measured values are accumulated some inconsistencies with the angle at the tip of the cone tool.

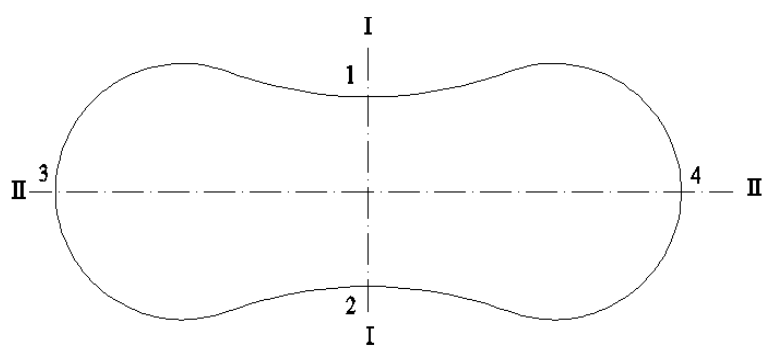

Fig. 8. Determination of the size b in different sections of the cutting contour

\section{CONCLUSION}

1. An approach is proposed to measure the detection error in 5-axis machines using the touch probe;

2. An approach is proposed to conpensate the postprocessor error for the particular machine;

3. The set-up error compensating approach has been verified in a virtual environment (Vericut) where it is determined that the deviation in the width of the cutting track falls within the accepted limits. 
Kaldashev. Method for Measuring Error Establishment in 5-Axis Milling Machines with a Touch Probe.

\section{REFERENCES}

[1] Angel Lengerov, Galina Nikolcheva, Julieta Kaleycheva, Lyubomir Lazov, Computer control the accuracy of the parts processed on cnc machine tools based on statistical process control, ,Vide. Tehnologija. Resursi- Environment, Technology, Resources 3, pp.179-182, 2017;

[2] Dimitrov D., Karachorova V., Nenov G., Research the possibilities of the method for determining the tolerances in geometric precision of machining center, Machines Technologies Materials, Issue 3, 2017, pp. 118-120, ISSN Print 1313-0226;
[3] Fanuc Series 30i/31i/32i-Model B, Operator Manuals for machining center system

[4] Graham T. Smith, CNC machining technology 3, Part programming technique, Springer Verlag, London, 1993, ISBN 978-1-4471-17-48-3;

[5] Hadzhiyski P., Knives for rotary dies with variable geometry, Journal "Engineering and automations problems", 2011, p. 131135, ISSN 0234-6206; 